\title{
The broad-spectrum antibiotic, zeamine, kills the nematode worm Caenorhabditis elegans
}

\author{
Josephine E. E. U. Hellberg ${ }^{1}$, Miguel A. Matilla ${ }^{1,2}{ }^{*}$ and George P. C. Salmond ${ }^{1}$ * \\ ${ }^{1}$ Department of Biochemistry, University of Cambridge, Cambridge, UK \\ ${ }^{2}$ Department of Environmental Protection, Estación Experimental del Zaidín - Consejo Superior de Investigaciones Científicas, Granada, Spain
}

\section{Edited by:}

Enrica Pessione, University of Torino, Italy

\section{Reviewed by:}

Linda Thomashow, United States

Department of Agriculture -

Agricultural Research Service, USA

Paul Alan Hoskisson, University of

Strathclyde, UK

\section{*Correspondence:}

George P. C. Salmond, Department of

Biochemistry, University of

Cambridge, Tennis Court Road,

Cambridge CB2 10W, UK

e-mail:gpcs2@cam.ac.uk;

Miguel A. Matilla, Department of

Environmental Protection, Estación

Experimental del Zaidín - Consejo

Superior de Investigaciones

Científicas, Profesor Albareda 1,

Granada 18008, Spain

e-mail:miguel.matilla@eez.csic.es
Soil bacteria can be prolific producers of secondary metabolites and other biologically active compounds of economic and clinical importance. These natural products are often synthesized by large multi-enzyme complexes such as polyketide synthases (PKSs) or non-ribosomal peptide synthases (NRPSs). The plant-associated Gram-negative bacterium, Serratia plymuthica A153, produces several secondary metabolites and is capable of killing the nematode worm Caenorhabditis elegans; a commonly used model for the study of bacterial virulence. In this study, we show that disruption of the hybrid PKS/NRPS zeamine $(z \mathrm{mn})$ gene cluster results in the attenuation of "fast-killing" of $C$. elegans, indicating that zeamine has nematicidal activity. C. elegans also exhibits age-dependent susceptibility to zeamine, with younger worms being most sensitive to the bioactive molecule. The $z m n$ gene cluster is widely distributed within Serratia and phytopathogenic Dickeya species and investigation of strains harboring the zmn gene cluster showed that several of them are highly virulent in $C$. elegans. Zeamine was described previously as a phytotoxin and broadspectrum antibacterial compound. In addition to its nematicidal properties, we show here that zeamine can also kill Saccharomyces cerevisiae and Schizosaccharomyces pombe. The expression of the $z m n$ gene cluster and regulation of zeamine production were also investigated. Transcription of the cluster was growth phase-dependent, and was modulated by the post-transcriptional RNA chaperone, Hfq. The results of this study show that zeamine is a highly toxic molecule with little, or no, apparent host specificity in very diverse biological systems. In its current form, zeamine(s) may be useful as a lead compound suitable for chemical modification and structure-activity assays. However, because of widespread nonselective toxicity in multiple bioassays, unmodified zeamine(s) is unlikely to be suitable as a therapeutic antibiotic.

Keywords: Serratia plymuthica, Dickeya, secondary metabolite, PKS, NRPS, antibiotic, Caenorhabditis elegans, zeamine

\section{INTRODUCTION}

Bacteria belonging to the Gram-negative genus Serratia are members of the $\gamma$-proteobacterial family Enterobacteriaceae. The best characterized member of the genus, Serratia marcescens, was first described in 1819 as a pigmented microbial isolate (Grimont and Grimont, 1978). Serratia species are ecologically diverse although strains of Serratia plymuthica are commonly isolated from soil as well as from the rhizosphere of wheat ( $\AA$ ström and Gerhardson, 1988), oilseed rape (Neupane et al., 2012a,b,c), melon (Kamensky et al., 2003), and pea (Gould et al., 2008), the anthosphere of oil pumpkin (Fürnkranz et al., 2012) and from rotting potato tissue (Czajkowski et al., 2012). Many strains of S. plymuthica are capable of producing compounds with antibiotic activity, such as the antifungal and anti-oomycete haterumalide, oocydin A (Levenfors et al., 2004), and the antifungal pyrrolnitrin (Liu et al., 2007). Several S. plymuthica strains were shown to be effective as biocontrol agents (De Vleesschauwer and Höfte, 2003), for example being capable of controlling the phytopathogenic gray mold Botrytis cinerea and white mold, Sclerotina sclerotiorum, on greenhousegrown melon (Kamensky et al., 2003), as well as suppressing the growth of Penicilliumblue and green mold on citrus fruit (Meziane et al., 2006). The strain used in this study, S. plymuthica A153, was isolated from the rhizosphere of wheat (Aström and Gerhardson, 1988), despite producing phytopathogen-antagonistic compounds (Thaning et al., 2001; Levenfors et al., 2004). Recently, the strain has also been shown to be virulent in the Caenorhabditis elegans animal infection model (Matilla et al., 2012).

Caenorhabditis elegans is a free-living nematode that reaches an adult length of 1-2 mm. Although first developed as a genetic model in the 1970s (Brenner, 1974), C. elegans has undergone a renaissance over the past decade as a model system for assaying and understanding bacterial pathogenesis (Sifri et al., 2005). The importance of this has been two-fold. Firstly, not only are some soil-dwelling nematodes agricultural pests that attack economically important crops (reviewed by Jones et al., 2013) but they are also hard to control with traditional pesticides, and that makes nematode-pathogenic bacteria attractive as potential biocontrol agents (Chitwood, 2002). Secondly, although nematodes and mammals are separated by over 900 million years of evolution (Hedges et al., 2006), there are a surprising number of 
bacterial virulence factors affecting both taxa (Rahme et al., 2000). Altogether, C. elegans has become a useful model for the identification of novel virulence factors and the characterization of the relationships between pathogens and genetically amenable hosts (Sifri et al., 2005).

Bacteria are capable of antagonizing C. elegans by several mechanisms (Sifri et al., 2005). The most common of these is bacterial colonization of the nematode intestine, where bacteria accumulate in the intestinal lumen (causing it to expand) and interfere with its normal function (Sifri et al., 2005). This is the mechanism by which many human pathogens - such as Salmonella typhimurium (Aballay et al., 2000), Pseudomonas aeruginosa (Mahajan-Miklos et al., 1999), and S. marcescens (Kurz et al., 2003) - infect C. elegans. This type of 'worm killing, also referred to as 'slow killing,' takes place over the span of several days and correlates with bacterial proliferation in the intestine (Sifri etal., 2005; Portal-Celhay et al., 2012). On the other hand, some bacteria are capable of killing worms over much shorter time-spans. This 'fast killing' is usually mediated by toxins that are produced by the bacteria (Sifri et al., 2005). Although toxic proteins have been described (Wei et al., 2003), the toxins are typically secondary metabolites. For example, $P$. aeruginosa PA14 is capable of killing $C$. elegans through oxidative stress by using the phenazine compound pyocyanin as a virulence factor (Mahajan-Miklos et al., 1999; Cezairliyan et al., 2013).

Secondary metabolites are traditionally considered to be nonessential organic molecules that are synthesized by cells during the later stages of growth, without playing any direct role in growth or development (Price-Whelan etal., 2006). Although the true roles of secondary metabolites remain elusive, some of them can confer fitness advantages to producing bacteria. Thus, secondary metabolites with antibiotic activity are thought to increase the fitness of bacteria in complex natural environments by antagonizing microbial competitors (Mazzola et al., 1992) or by deterring predation (Pradel et al., 2007). Additionally, since soil is a stressful environment where nutrients are limited (Challis and Hopwood, 2003), it has been speculated that soil bacteria are enriched for the production of secondary metabolites performing primary functions acting, for example, as synergistic siderophores (PriceWhelan et al., 2006). Many secondary metabolites are synthesized by large multidomain proteins such as non-ribosomal peptide synthases (NRPSs) or polyketide synthases (PKSs) (Sattely et al., 2008). Frequently, the genes encoding these enzymes are carried on the biosynthetic gene clusters together with the genes for tailoring enzymes responsible for the modification of the final structure of the molecule (Osbourn, 2010). The modular and mobile nature of biosynthetic gene clusters can enable the mixed assembly of biosynthetic genes from different sources to form hybrid gene clusters containing both NRPS- and PKS-encoding genes.

Preliminary work in this laboratory showed that S. plymuthica A153 is a nematode-pathogen capable of killing C. elegans rapidly (Matilla etal., 2012), suggesting that it produced a nematicide toxin. In this study we investigated the relationship between A153 and C. elegans to characterize the pathogen-worm interaction, with particular emphasis on identifying the A153 nematicide, genes involved in its biosynthesis and the regulation thereof.

\section{MATERIALS AND METHODS STRAINS, PLASMIDS, PHAGES, CULTURE MEDIA, AND GROWTH CONDITIONS}

Bacterial strains, plasmids, and phages used in this study are listed in Table 1. Serratia, Dickeya, and derived strains were grown at $30^{\circ} \mathrm{C}$, unless otherwise indicated, in $\mathrm{L}$ broth (LB, per liter: $5 \mathrm{~g}$ yeast extract, $10 \mathrm{~g}$ tryptone, $5 \mathrm{~g} \mathrm{NaCl}$ ), potato dextrose (16 g of potato dextrose broth $\left.\mathrm{l}^{-1}\right)$, minimal medium [MM: 0.1\% (w/v) $\left(\mathrm{NH}_{4}\right)_{2} \mathrm{SO}_{4}, 0.41 \mathrm{mM} \mathrm{MgSO}_{4}$,

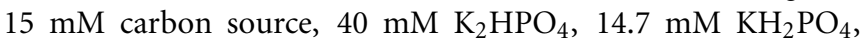
$\mathrm{pH}$ 6.9-7.1], optimized minimal medium [OMM: 0.2\%(w/v) $\left(\mathrm{NH}_{4}\right)_{2} \mathrm{SO}_{4}, 1.66 \mathrm{mM} \mathrm{MgSO}, 0.2 \%(\mathrm{w} / \mathrm{v})$ mannitol, $0.2 \%$ (w/v) glycerol, $60.3 \mathrm{mM} \mathrm{K}_{2} \mathrm{HPO}_{4}, 33.1 \mathrm{mM} \mathrm{KH_{2 }} \mathrm{PO}_{4}, 15.9 \mu \mathrm{M}$ $\mathrm{MnCl}_{2}, 90.1 \mu \mathrm{M} \mathrm{CaCl} 2,32.9 \mu \mathrm{M} \mathrm{FeSO}$ ], 1-carbon OMM [1C-OMM: 0.2\% (w/v) $\left(\mathrm{NH}_{4}\right)_{2} \mathrm{SO}_{4}, 1.66 \mathrm{mM} \mathrm{MgSO}_{4}, 15 \mathrm{mM}$ carbon source, $60.3 \mathrm{mM} \mathrm{K}_{2} \mathrm{HPO}_{4}, 33.1 \mathrm{mM} \mathrm{KH} \mathrm{PO}_{4}, 15.9 \mu \mathrm{M}$ $\mathrm{MnCl}_{2}, 90.1 \mu \mathrm{M} \mathrm{CaCl}, 32.9 \mu \mathrm{M} \mathrm{FeSO}$ ]. Escherichia coli strains were grown at $37^{\circ} \mathrm{C}$ in LB. E. coli $\mathrm{DH} 5 \alpha$ was used for gene cloning. Media for propagation of E. coli $\beta 2163$ was supplemented with $300 \mu \mathrm{M}$ 2,6-diaminopimelic acid. Where appropriate, antibiotics were used at the following final concentrations (in $\mu \mathrm{g} \mathrm{mL}^{-1}$ ): ampicillin, 100; kanamycin, 25 (E. coli), 75 (Serratia); streptomycin, 50; tetracycline, 10. Sucrose was added to a final concentration of $10 \%(\mathrm{w} / \mathrm{v})$ to select for derivatives of a second crossover event during marker exchange mutagenesis. C. elegans was maintained at $15^{\circ} \mathrm{C}$ using standard methods (Brenner, 1974). Saccharomyces cerevisiae and Schizosaccharomyces pombe were grown at $30^{\circ} \mathrm{C}$ in yeast peptone dextrose (YPD, per liter: $10 \mathrm{~g}$ yeast extract, $20 \mathrm{~g}$ peptone, $20 \mathrm{~g}$ glucose).

\section{DNA TECHNIQUES, DNA MANIPULATION, AND BIOINFORMATICS ANALYSES}

Plasmid DNA was isolated using the Anachem Keyprep plasmid DNA kit. Manufacturer's instructions were followed for DNA digestion (New England Biolabs). The Anachem gel recovery kit was used to recover DNA from agarose gels. Ligation reactions and total DNA extraction were performed using standard protocols (Sambrook et al., 1989). Competent cells were prepared using calcium chloride and transformations were performed using standard protocols (Sambrook etal., 1989). PCR fragments for cloning were amplified using Phusion $^{\circledR}$ high fidelity DNA polymerase (New England Biolabs), and all sequences were confirmed. DNA sequencing was performed at the University of Cambridge DNA Sequencing Facility on an Applied Biosystems 3730xl DNA analyzer. Genome comparison analyses were performed using the wgVISTA on-line tool (Frazer etal., 2004). Open reading frames (ORFs) in the zeamine (zmn) gene cluster were predicted using Glimmer 3.0 (Delcher etal., 1999). BLAST was used for functional gene assignment. Protein domain organization was identified using the NCBI conserved domains database (Marchler-Bauer et al., 2011). 
Table 1 | Strains, phages, and plasmids used in this study.

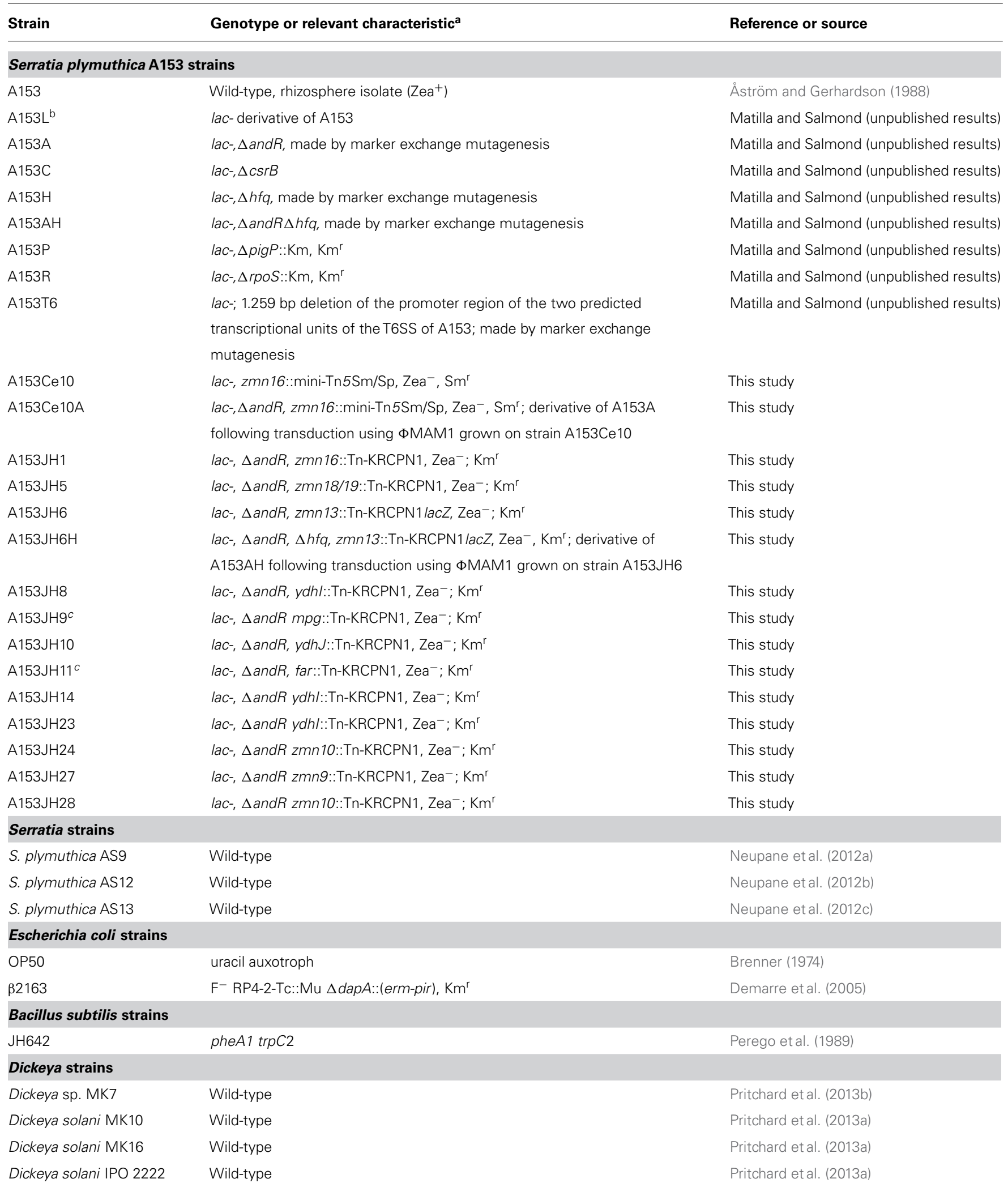


Table 1 | Continued

\begin{tabular}{|c|c|c|}
\hline Strain & Genotype or relevant characteristic ${ }^{a}$ & Reference or source \\
\hline Dickeya sp. NCPPB 3274 & Wild-type & Pritchard et al. (2013b) \\
\hline \multicolumn{3}{|l|}{ Fungal strains } \\
\hline Verticillium dahliae 5368 & Wild-type, plant pathogen & J. Cooper \\
\hline \multicolumn{3}{|l|}{ Caenorhabditis elegans } \\
\hline DH26 & fer-15-(b26) & Caenorhabditis genetics center \\
\hline \multicolumn{3}{|l|}{ Bacteriophage } \\
\hline$\Phi M A M 1$ & Generalized transducing phage for S. plymuthica A153 & Matilla and Salmond (2014) \\
\hline pUT-mini-Tn5-Sm/Sp & Delivery plasmid for mini-Tn $5 \mathrm{Sm} / \mathrm{Sp}, \mathrm{Ap}^{r}, \mathrm{Sm}^{r}$ & de Lorenzo etal. (1990) \\
\hline pTRB30 & pQE-80L (Quiagen)-based expression vector, $\mathrm{Ap}^{r}$ replaced by $\mathrm{Km}^{r}, \mathrm{Km}^{r}$ & T. Blower \\
\hline pJEEUH13 & hfq expression vector, $\mathrm{Km}^{\mathrm{r}}$ & This study \\
\hline
\end{tabular}

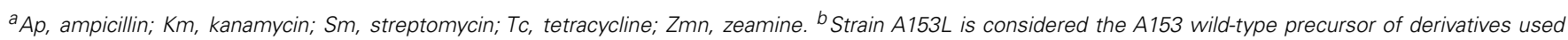

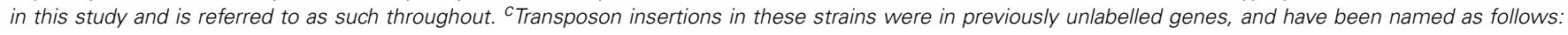
A153JH9, mannose-1-phosphate guanyltransferase (mpg); A153JH11, ferric aerobactin receptor (far).

\section{IN VITRO GROWTH KINETICS}

The kinetics of bacterial growth $\left(\mathrm{OD}_{600}\right)$ were measured with a Unicam He $\lambda$ ios spectrophotometer at $600 \mathrm{~nm}$, using bacterial cultures grown in $\mathrm{LB}$ or OMM at 215 r.p.m. at $25^{\circ} \mathrm{C}$, unless otherwise indicated. Three replicates were used for each condition and strain.

\section{RANDOM TRANSPOSON MUTAGENESIS, MUTANT SCREENING, AND GENERALIZED TRANSDUCTION}

Random transposon mutagenesis of A153 was performed by conjugation with $E$. coli $\beta 2163$ harboring plasmids containing transposons Tn-KRCPN1 or mini-Tn $5 \mathrm{Sm} / \mathrm{Sp}$, using a previously published protocol (Matilla etal., 2012). Mutant libraries for phenotypic screening were collected on antibiotic-selective plates before screening. Screening for mutants with reduced nematicidal activity was performed as described in Kurz et al. (2003), and screening for mutants with reduced antibacterial activity was performed as described by Zhou et al. (2011). To confirm that mutant phenotypes were associated with single insertions and to ensure association between mutation and phenotype, the mutations were transduced into the parent genetic background using the generalized transducing bacteriophage ФMAM1, as described in Matilla and Salmond (2014). Random-primed PCR and amplicon sequencing were used to identify transposon insertion points, as previously described Matilla et al. (2012). The genome of S. plymuthica A153 has been recently sequenced (Matilla and Salmond, unpublished results).

\section{PHENOTYPIC AND VIRULENCE ASSAYS}

Antibacterial and antifungal assays against Bacillus subtilis JH642 and Verticillium dahliae 5368, respectively, were performed as described in Matilla et al. (2012), at $25^{\circ} \mathrm{C}$ unless stated otherwise.
Assays for fungicidal activity against yeast were performed in the same manner as the antibacterial assays, but using overnight cultures S. cerevisiae and S. pombe grown in YPD. C. elegans virulence assays were performed as previously described Matilla et al. (2012), with the exception that synchronized worms were obtained by egg-lay, as described by Gems et al. (1998), with synchronized populations allowed to develop at $25^{\circ} \mathrm{C}$ to induce the fer- 15 sterility phenotype. Large-scale phenotypic screens for nematicidal activity were performed using around 50 synchronized L1-stage worms per well in 24-well plates (Kurz et al., 2003), where each well was inoculated with a transposon mutant for testing. Plates were incubated at $25^{\circ} \mathrm{C}$ and the survival of the worms was scored after 24 and 48 h. A Mantel-Cox log-rank test was used for statistical analysis of worm survival curves and was performed using Prism 5.0 (GraphPad Software). $P$ values of 0.05 and below were considered statistically significant.

\section{MEASUREMENT OF $\beta$-GALACTOSIDASE ACTIVITY}

Transcriptional fusion assays to detect expression of the lacZ reporter gene were performed as described previously (Ramsay, 2013), using the fluorogenic substrate 4-methylumbelliferyl $\beta$-Dgalactoside (MUG2). Gene transcription values were expressed as relative fluorescence units (r.f.u.) $\mathrm{s}^{-1} \mathrm{OD}_{600}{ }^{-1}$.

\section{QUANTIFICATION OF ZEAMINE ACTIVITY}

Quantification of A153 supernatant bioactivity was performed using cultures of the andrimid-negative mutant, A153A. Bacterial cells were grow at $25^{\circ} \mathrm{C}$, for $72 \mathrm{~h}$, in $\mathrm{MM}$ supplemented with one of the 15 different carbon sources tested. Cultures were harvested after $72 \mathrm{~h}$ and culture supernatants were sterile-filtered $(0.2 \mu \mathrm{m})$. Supernatant bioactivity (given as zeamine activity, $\mathrm{Z}_{\mathrm{A}}$ ) 
was determined using a B. subtilis antibacterial bioassay (Matilla et al., 2012), and given as the fraction of the diameter of the resultant halo $(\mathrm{H})$ and the diameter of the well (W) over the maximum $\mathrm{OD}_{600}$ attained by the bacteria in the relevant media.

\section{GENETIC COMPLEMENTATION OF $\triangle \mathrm{hfq}$}

For single-copy complementation of the in-frame $h f q$ deletion mutant $\mathrm{A} 153 \mathrm{H}$, an inducible plasmid construct was first generated, using wild-type $h f q$. For this, the A153 $h f q$ ORF was amplified using primers hfq-BamHI $\left(5^{\prime}\right.$-TAAT TCCGCTAAGGGGCAATCTTTGCA-3 $\left.{ }^{\prime}\right)$ and hfq-PstI (5'-TAATC TGCAGCTCGCAACGCGCTTTATTC- $\left.3^{\prime}\right)$. The PCR product was digested with PstI and BamHI and inserted at the same sites in the vector pTRB30. The resulting plasmid, pJEEUH13, was introduced into $\mathrm{A} 153 \mathrm{H}$ by electroporation. Gene expression was induced with $0.1 \mathrm{mM}$ IPTG.

\section{RESULTS}

CHARACTERIZATION OF A153 FAST-KILLING OF Caenorhabditis elegans

It has been reported previously that Serratia spp. such as $S$. marcescens (Kurz and Ewbank, 2000) and Serratia sp. ATCC 39006 (Coulthurst et al., 2004) are capable of killing C. elegans over the span of 3-5 days by establishing an infection in the nematode intestine. We observed that S. plymuthica A153 is capable of killing worms quickly, within hours (Figure 1). To better understand this interaction, the A153 killing dynamics of C. elegans were subjected to an initial characterization, whereby C. elegans L4 larvae were transferred from the standard C. elegans food-source E. coli OP50 onto lawns of A153. After transfer, the worms succumbed in stages. Initially, they were strongly repulsed by the bacteria and showed strong avoidance of the bacterial lawn. The immediacy of this effect suggests that the bacteria may produce odorants or surfactants that deter nematode grazing (Pradel et al., 2007; Burlinson et al., 2013). Worms that remained on the bacterial lawn quickly become immobilized, within hours of transfer, and remained alive for a latency period of about $6 \mathrm{~h}$, before they started dying. While immobilized, but before death, worms showed little to no spontaneous movement, although the pharynx and body wall muscles could be induced to contract by the gentle touch of an instrument. The majority of worms were dead within $24 \mathrm{~h}$ of transfer. The speed of A153 killing of C. elegans suggested that A153 produces a fast-acting nematicide that functions as a potent virulence factor in the nematode infection model.

\section{Caenorhabditis elegans SHOW AGE-DEPENDENT SENSITIVITY TO A153 FAST-KILLING}

The age of individual C. elegans has been shown previously to determine worm susceptibility to bacterial pathogens. Some fastkilling bacterial toxins such as pyocyanin have been shown to be more toxic to younger worms (Mahajan-Miklos et al., 1999). In contrast, under slow-killing infection models, older worms are generally more sensitive (Laws et al., 2004; Portal-Celhay et al., 2012). To determine if there were any age-dependent susceptibility effects to A153 fast-killing of C. elegans, worms from each of the four C. elegans larval stages (L1-L4) and day-1 and day-2 adults were transferred onto lawns of A153 and nematode survival was

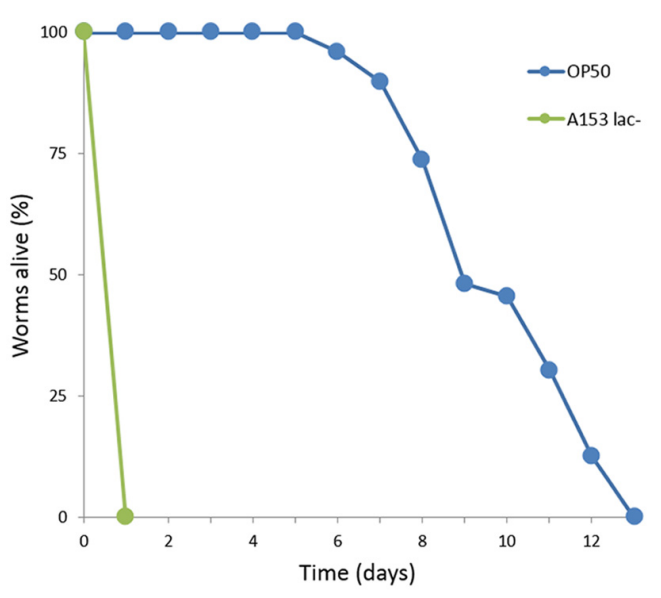

FIGURE 1 | Serratia plymuthica A153 antagonizes Caenorhabditis elegans. Survival of $C$. elegans when cultured on S. plymuthica A153. The results of a representative trial with at least 50 worms under each condition is shown.

assayed hourly. The results revealed that C. elegans show significant age-dependent differential susceptibility to the A153 nematicide, with early larvae being more sensitive than late larvae (Figure 2; L1 vs. L4: $P<<0.05$ ), and with larvae being more sensitive than adult worms (Figure 2; L4 vs. d1: $P<<0.05$ ). This shows that A153 fast-killing and C. elegans susceptibility to the A153 nematicide is inversely correlated with the developmental stage and age of the worm.

\section{ISOLATION OF A153 MUTANTS WITH REDUCED VIRULENCE AGAINST C. elegans}

To identify the genes involved in A153 fast-killing of C. elegans, a mutant library was generated using random transposon mutagenesis. In an initial screen, the library was screened looking for mutants with reduced nematicidal activity against L1-stage larvae.

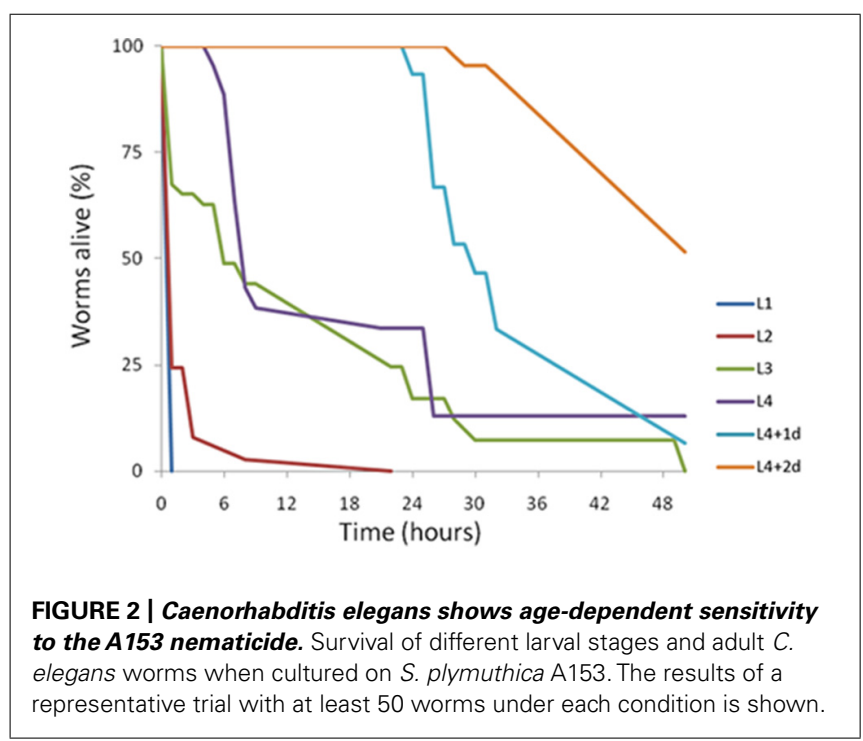


This approach yielded one mutant, A153Ce10, which showed significantly reduced 'fast-killing' of worms. This mutant still showed wild-type antibacterial (Figure 3A) and antifungal (Figure 3B) activities, suggesting that A153Ce10 is specifically deficient in worm-killing. Random-primed PCR confirmed that the transposon in A153Ce10 was in the gene zmn16, encoding a putative thioester reductase, and forming part of a hybrid FAS/PKS/NRPS gene cluster responsible for the biosynthesis of the broad-spectrum antibacterial antibiotic, zeamine (zmn), which was first described by Masschelein et al. (2013).

Zeamine was first identified in the plant pathogen Dickeya zeae EC1 as a phytotoxic virulence factor with antibacterial properties (Wu etal., 2010; Zhou et al., 2011), and our results suggest that zeamine also has nematicidal activity. In A153, the
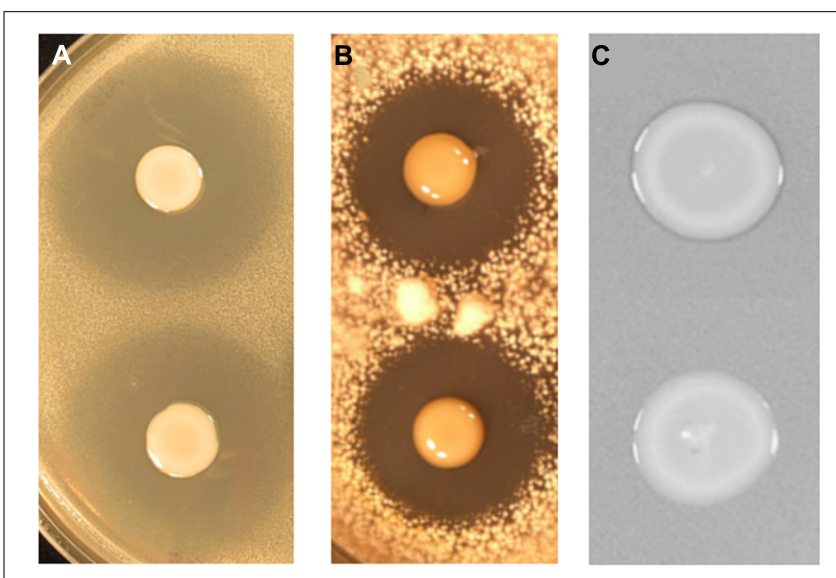

FIGURE 3 | Serratia plymuthica A153 mutants that show reduced virulence in $C$. elegans are specifically attenuated for zeamine production. Plate-based bioassays showing andrimid $(A)$ oocydin $A(B)$ and zeamine (C) production. (A,B) The upper culture spot shows the A153 wild-type whereas the lower culture spot shows the derived mutant A153Ce10. (C) The upper culture spot shows the A153 $\Delta$ andR mutant A153A whereas the lower culture spot shows the derived mutant A153Ce10A, which is representative of all mutants characterized in this study. In all cases, plates were incubated at $25^{\circ} \mathrm{C}$ either overnight $(\mathbf{A}, \mathbf{C})$ or for 5 days (B). antibacterial activity of zeamine was masked by the production of another potent antibiotic, andrimid (cf. Figures 3A,C; Matilla and Salmond, unpublished results). Using a mutant defective in the production of this antibacterial compound, A153A, a random transposon mutant library was constructed and screened for mutants lacking the small halo associated with the production of zeamine by A153 (Figure 3C). Six mutants showing no, or reduced, antibacterial activity (A153JH1, A135JH5, A153JH6, A153JH24, A153JH27, and A153JH28) and with transposon insertions in the $z m n$ gene cluster (Figure 4A) were isolated. These mutants showed significantly reduced nematicidal activity compared to that of the A153A parent strain $(P<<0.05$; Figure 5A, Figure S1), confirming that zeamine is indeed the A153 nematicide and responsible of the observed A153 fast-killing of C. elegans.

The A153 zmn gene cluster spans over $54 \mathrm{~kb}$ and contains 22 genes $(z m n 1-22)$, organized into three putative operons (Figure 4A; Table S1). As previously described in S. plymuthica RVH1, the A153 zmn gene cluster contains the genes for three multidomain PKSs (zmn10, zmn11, zmn18) and two multidomain NRPSs (zmn16, zmn17). In addition to these biosynthetic genes, the cluster also contains genes encoding modifying enzymes (zmn3, zmn12, zmn14, zmn15, zmn22) and transportrelated proteins $(z m n 7, z m n 8, z m n 9, z m n 20, z m n 21)$ - the latter with a proposed role in conferring innate resistance to the zeamine antibiotic (Masschelein et al., 2013). A putative integrase-encoding gene marks the downstream end of the cluster, suggesting that it could have been acquired by horizontal gene transfer.

\section{THE zmn GENE CLUSTER IS WIDELY DISPERSED WITHIN Serratia AND Dickeya GENERA}

Genome comparison analyses revealed that the $z m n$ gene cluster is present in S. plymuthica strains AS9, AS12, AS13, A30, S13, and V4 (Table S2). Additionally, we also identified the biosynthetic gene cluster in several phytopathogenic strains belonging to the Dickeya genus, including D. solani MK10, MK16, IPO222; D. zeae DZ2Q and ZJU1202; and Dickeya spp. MK7 and NCPPB 3274 (Table S2). The Serratia and Dickeya zmn clusters span between 50.64- and 54.02-Kbp and are between 59.7 and 96.4\%

A

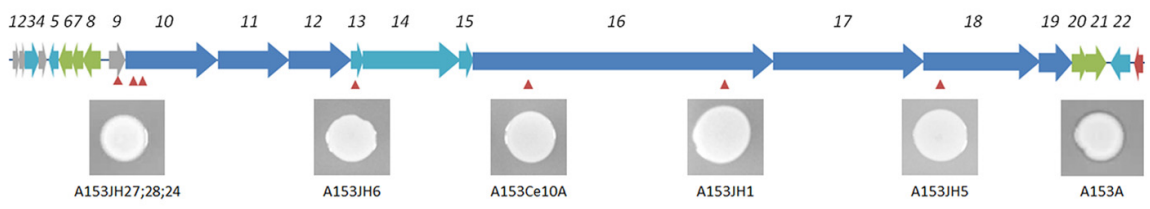

B

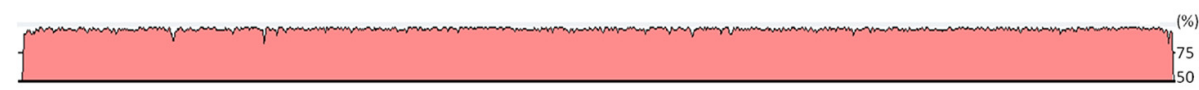

C

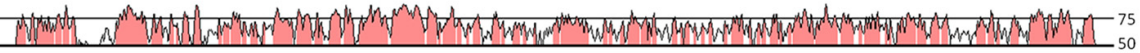

FIGURE 4 | The zeamine gene cluster is present in Serratia and

Dickeya strains. Genetic organization of the $z m n$ gene cluster sequence in S. plymuthica A153 (A). Location of the Tn-KRCPN1 transposon insertions are indicated by red arrowheads. Inserts show mutant antibacterial phenotypes against $B$. subtilis after an overnight incubation at $25^{\circ} \mathrm{C}$. Note the panel depicting the phenotype of the $\mathrm{A} 153 \mathrm{\Delta andR}$ parent strain to the far right. DNA homology (\%) between the $z m n$ gene cluster of $\mathrm{A} 153$ and those of $S$. plymuthica RVH1 (B) and D. solani MK10 (C) is presented. Sequence comparisons were performed using wgVISTA and show regions of $>50 \%$ homology. 

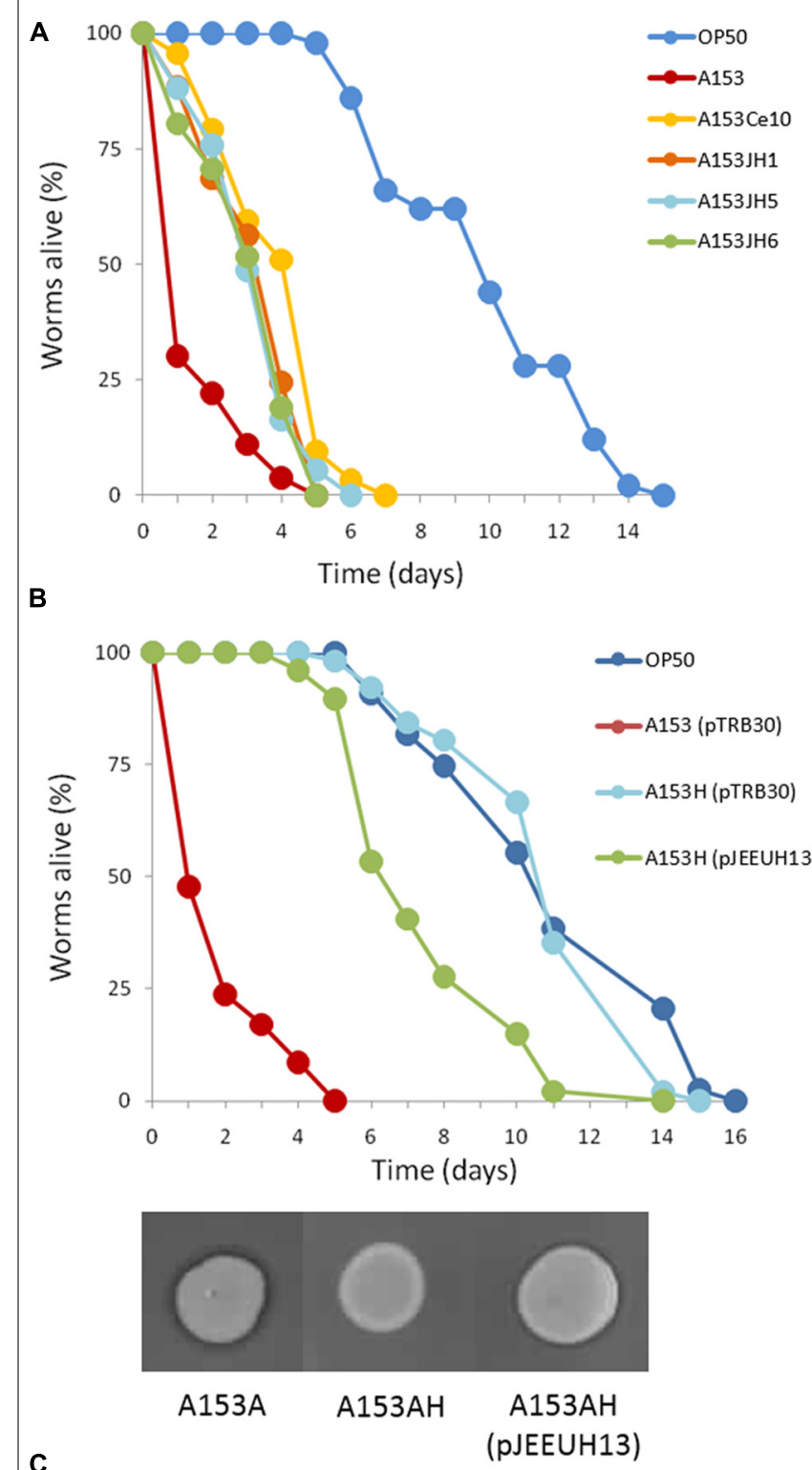

C

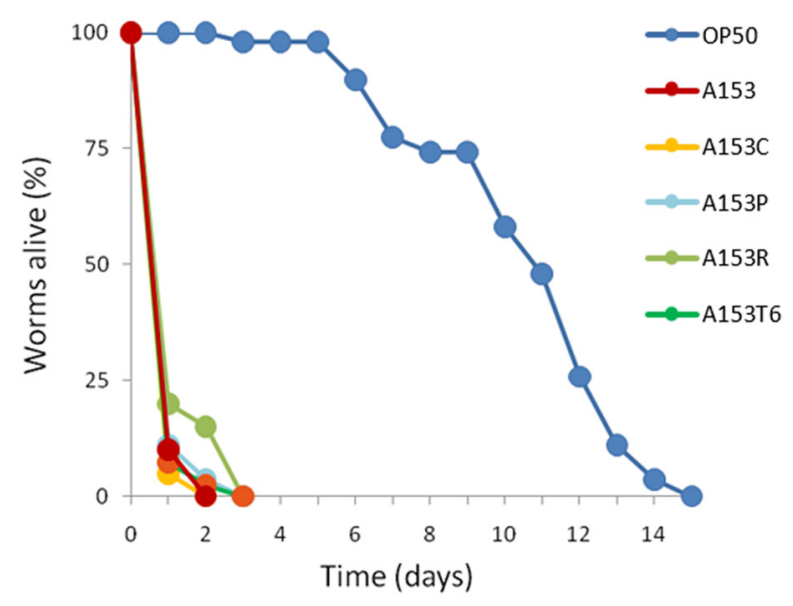

FIGURE 5 | Continued

\section{FIGURE 5 | Continued}

Kinetics of the nematicidal properties of Serratia plymuthica A153

strains. (A) Mutation of the zmn gene cluster attenuates $S$. plymuthica A153 fast killing of $C$. elegans. Compared with the A153A parent strain, mutants $\mathrm{A} 153 \mathrm{JH} 1, \mathrm{~A} 153 \mathrm{JH} 5, \mathrm{~A} 153 \mathrm{JH} 6$ and $\mathrm{A} 153 \mathrm{Ce} 10 \mathrm{~A}$, show reduced virulence in $C$. elegans $(P<<0.05)$. (B) Mutation of the chaperone $\mathrm{Hfq}$ eliminates $A 153$ virulence in $C$. elegans. The virulence could be partially restored by the in trans expression of $h f q$ (using plasmid pJEEUH13). Gene expression was induced using $0.1 \mathrm{mM}$ IPTG. Inserts show antibacterial phenotypes of the parent and complemented strains after an overnight incubation at $25^{\circ} \mathrm{C}$. (C) Mutation of the regulators rpoS, pigP, and $\operatorname{csr} B$ had no effect on $A 153$ fast-killing of $C$. elegans, and neither did deletion of the A153 T6SS. For each experiment, worms were transferred at the L4 stage and the results of one representative trial with at least 50 worms under each condition is shown.

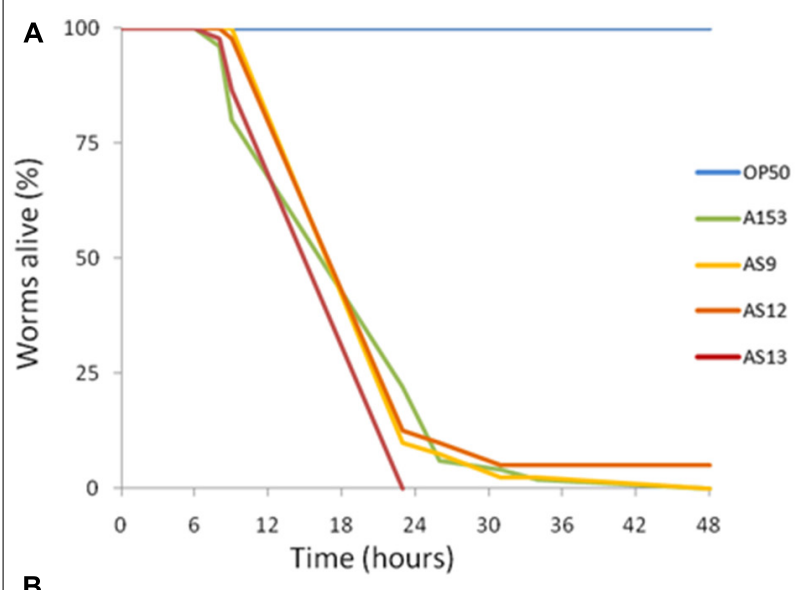

B

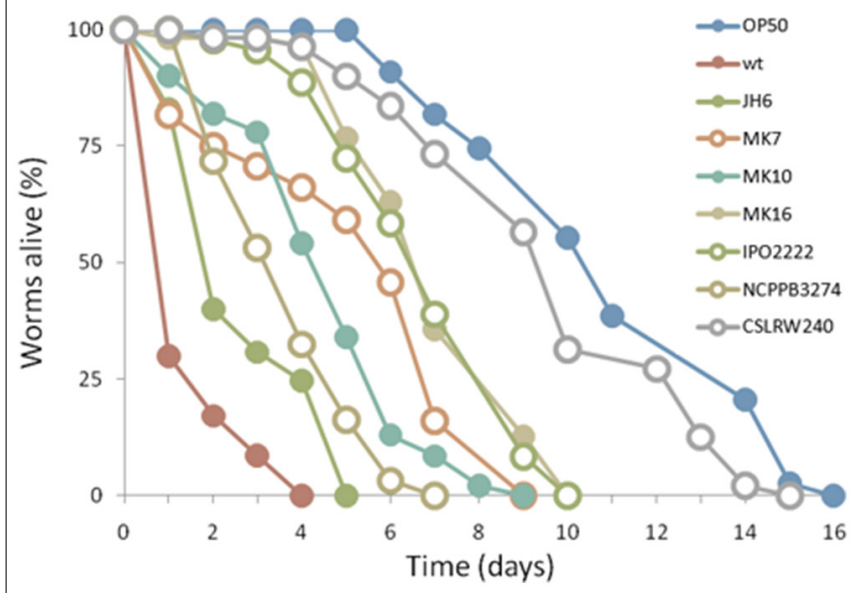

FIGURE 6 | Virulence of enterobacterial strains harboring the zmn gene cluster. The pigmented S. plymuthica strains AS9, AS12 and AS13 show fast killing of $C$. elegans (A). In contrast, D. solani strains MK10, MK16, IPO2222 and Dickeya spp. MK7 and NCPPB3274 showed no fast killing of C. elegans (B). For each experiment, worms were transferred at the L4 stage and the results of a representative trial with at least 50 worms under each condition is shown.

identical at the DNA level with the A153 zmn gene cluster (Table S3).

In silico analyses showed that the A153 and RVH1 zmn gene clusters have the same gene and domain organization (Figure 4B). 


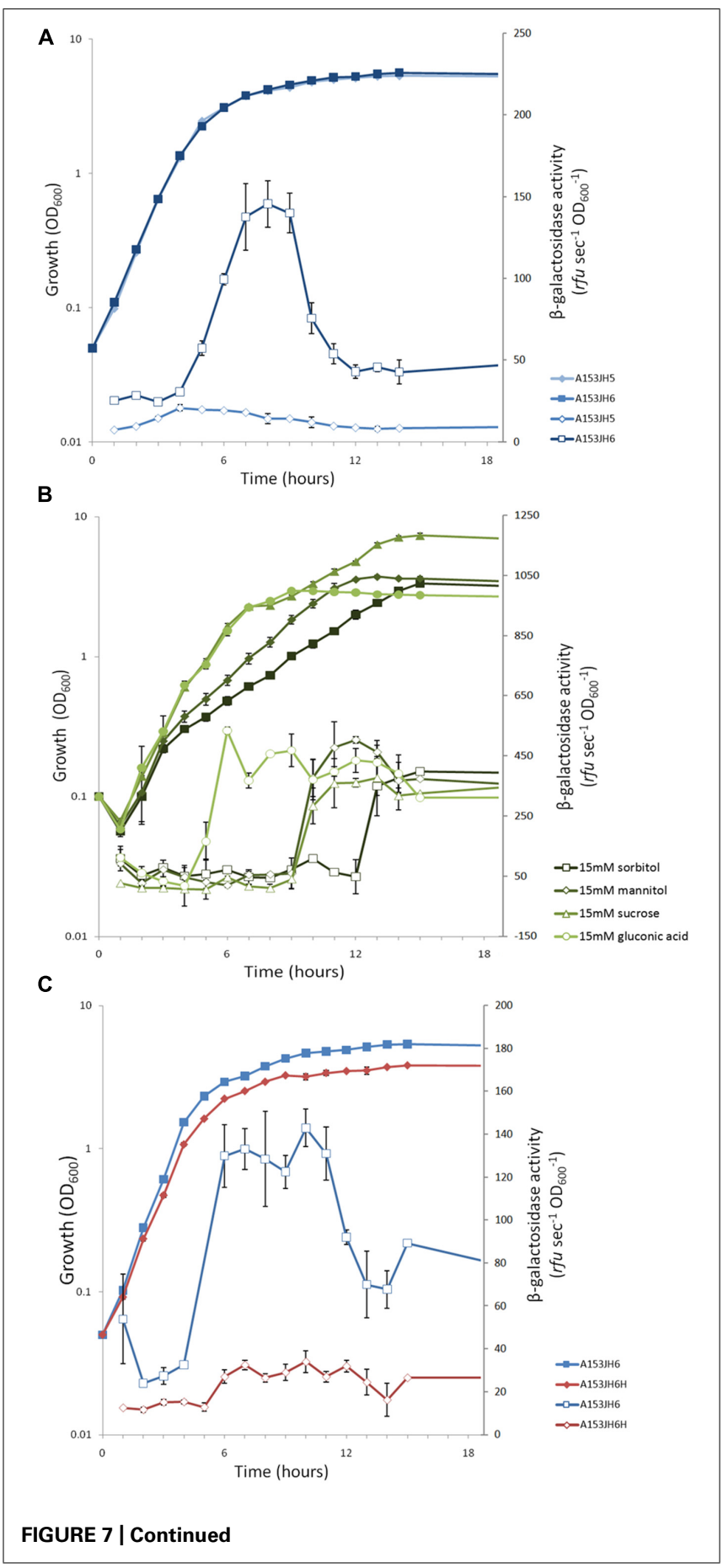

However, we found that the A153 PKS Zmn10 contains a previously unidentified dehydratase (DH) domain. Based on the high sequence identity (around 95\%) between $z m n$ gene clusters in A153 and related S. plymuthica strains, we hypothesized that all these strains could possess high nematicidal activities. Thus, using L4-stage larvae, we showed that S. plymuthica strains AS9, AS12, and AS13 are highly virulent and capable of killing C. elegans at similar levels to those of A153, with $50 \%$ of worms dying within $18 \mathrm{~h}$ of transfer (Figure 6A).

\section{FIGURE 7 | Continued}

The expression of the S. plymuthica A153 zmn gene cluster is growth phase-dependent and post-transcriptionally regulated by the RNA chaperone Hfq. (A) Transcription of the zmn gene cluster throughout growth in Serratia plymuthica A153. The dip in $\beta$-galactosidase activity post-peak suggests the enzyme is subject to proteolytic turnover, which has been observed previously in A153 (Matilla and Salmond, unpublished results). (B) Different carbon sources have different effects on the correlation between zmn gene transcription and the bioactivity of A153A-derived supernatants. $\beta$-galactosidase activity was measured in strain A153JH6 grown in 1C-OMM supplemented with $15 \mathrm{mM}$ sorbitol, mannitol, sucrose, or gluconic acid. (C) Expression of the zmn gene cluster is regulated by the RNA chaperone Hfq. $\beta$-galactosidase activity was measured in strain A153JH6 in the presence (red) or absence (blue) of a chromosomal $h f q$ gene deletion. $(\mathbf{A}, \mathbf{B})$ The strains were grown in $L B$ at $25^{\circ} \mathrm{C}$ and $\beta$-galactosidase activities were measured in strains expressing chromosomal zmn13::lacZ fusions. In all panels solid symbols represent growth of the corresponding strains whereas open symbols represent $\beta$-galactosidase activity. Data shown are the average values $\pm S D$ of at least three experiments.

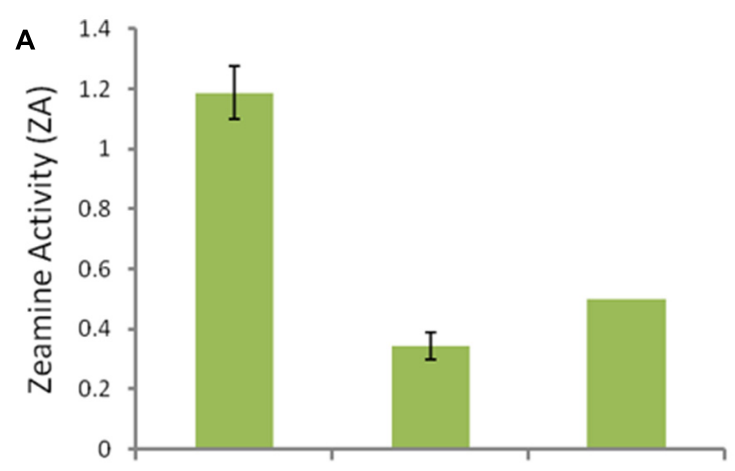

B. subtilis S. cerevisiae Sch.pombe

B

A153A

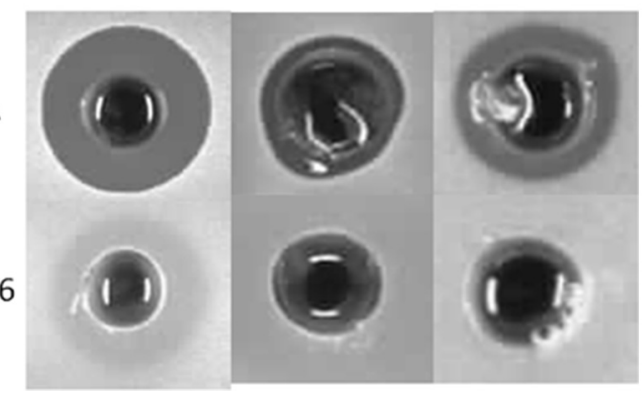

FIGURE 8 | Zeamine is toxic to the ascomycete yeasts Saccharomyces cerevisiae and Schizosaccharomyces pombe. (A) Bioactivity of cell-free supernatants of A153A show bioactivity against Bacillus subtilis and the ascomycete yeasts $S$. cerevisiae and S. pombe. A153 strains were grown in $\mathrm{OMM}$ at $25^{\circ} \mathrm{C}$ for $48 \mathrm{~h}$ and the bioactivities were quantified from bioassay plates incubated overnight at $30^{\circ} \mathrm{C}$. Data shown are average values $\pm S D$ from at least three experiments. (B) Supernatants from stationary phase cultures of A153JH6 grown under the same conditions produce no antibiotic halos on bioassay plates, confirming that the halos are produced by zeamine.

Importantly, pairwise comparisons in silico indicate that genes $z m n 1-4$ are not present in strains of Dickeya and that the $z m n 5$ homolog constitutes the first gene of these $z m n$ gene clusters 
(Figure 4C). In addition, whereas the $z m n$ gene clusters in different strains of Dickeya show around 60\% sequence identity with the A153 cluster, the putative permease $\mathrm{Zmn} 9$ is only about $50 \%$ conserved between the genera. The NCBI conserved domains database predicts that the Serratia Zmn9 contains a zinc-dependent phospholipase domain, whereas Zmn9 in Dickeya is predicted to contain a CDP-alcohol phosphatidyltransferase domain. To investigate if strains of Dickeya show similar nematicidal differences to $z m n$-carrying strains of Serratia despite these differences, a subset of Dickeya strains that carry the $z m n$ gene cluster (MK7, MK10, MK16, IPO2222, and NCPPB 3274) were chosen for $C$. elegans virulence assays. Interestingly, although the tested Dickeya strains had variable pathogenic capacity against L4-stage C. elegans (Figure 6B), none of them was found to show the fast-killing phenotype observed in strains of S. plymuthica that carry the $z m n$ gene cluster.

\section{THE zmn GENE CLUSTER IS TRANSCRIBED IN A GROWTH PHASE-DEPENDENT MANNER}

To investigate the transcription of the $z m n$ gene cluster, $\beta$ galactosidase activity was measured in a chromosomal zmn13::lacZ fusion strain (strain A153JH6). Transcription of $z m n$ biosynthetic genes started in mid-logarithmic phase of growth and reached an apparent maximum in early stationary phase of growth (Figure 7A). The sharp decrease in $\beta$-galactosidase levels beyond this point may be explained by proteolytic turnover of $\beta$-galactosidase (Matilla and Salmond, unpublished results).

\section{THE PRODUCTION OF ZEAMINE IS CARBON SOURCE-DEPENDENT}

Zeamine production has been shown previously to differ between growth media, being higher in D. zeae EC1 when grown in an OMM, compared to the standard LB culture medium (Zhou et al., 2011). Thus, we investigated zeamine production in strains grown in different carbon sources by determining the bioactivity of cell-free supernatants against $B$. subtilis, which is sensitive to zeamine (Figure 3C). Our results showed that the production of the bioactive molecule is carbon source-dependent, with some carbon sources favoring high levels of zeamine biosynthesis (e.g., sorbitol and mannitol) whereas others do not support the production of zeamine at all (e.g., gluconic acid; Table S4). Expression of the $z m n$ gene cluster, reported using $\beta$-galactosidase assays, was examined in a modified OMM with different carbon sources (1C-OMM). Unexpectedly, no correlation between $z m n$ gene transcription and zeamine production was observed (Figure 7B; Table S4).

\section{THE RNA CHAPERONE Hfq REGULATES THE PRODUCTION OF ZEAMINE AND THE EXPRESSION OF zmn BIOSYNTHETIC GENES}

The RNA chaperone Hfq acts as a regulator of gene expression by interacting with small regulatory RNAs to stabilize the interaction between these and their target mRNAs through the formation of regulatory RNA-RNA complexes (Vogel and Luisi, 2011). Mutants defective in $h f q$ are highly pleiotropic and can be attenuated in both virulence and the production of secondary metabolites in Serratia sp. ATCC39006 (Wilf et al., 2012). To investigate whether $\mathrm{Hfq}$ is involved in regulating the production of zeamine in S. plymuthica A153, C. elegans virulence assays were performed. The results showed that deletion of $h f q$ in strain $\mathrm{A} 153 \mathrm{H}$ strongly attenuated virulence to $C$. elegans L4 larvae $(P<<0.05$; Figure 5B). The virulence of $\mathrm{A} 153 \mathrm{H}$ could be partially restored by expressing $h f q$ in trans (Figure 5B). $\beta$-galactosidase assays showed that deletion of $h f q$ abolished the transcription of the $z m n$ gene cluster (Figure 7C), confirming that Hfq positively regulates the production of zeamine. It is well known that $\mathrm{Hfq}$ regulates the translation of the stationary-phase sigma factor RpoS (Vogel and Luisi, 2011). To investigate whether Hfq regulation is dependent on RpoS, we phenotypically characterized an rpoS mutant in A153. However, this mutant showed the same antibacterial and nematicidal activities as the wild-type strain (Figure 5C). Mutants defective in the non-coding small RNA csrB (Babitzke and Romeo, 2007) and the transcriptional regulator PigP (Fineran et al., 2005) were also unaffected in their virulence against $C$. elegans (Figure 5C).

\section{ZEAMINE IS TOXIC TO ASCOMYCETE YEASTS}

Zeamine shows some structural similarity to another family of hybrid polyamino-polyketides: fabclavines. These natural products have been shown to have broad-spectrum antibiotic activity against a diverse set of organisms including bacteria and ascomycete fungi (Fuchs et al., 2014). Using cell-free supernatants of A153A and A153JH6, we showed that zeamine is bioactive against the ascomycete yeasts $S$. cerevisiae and S. pombe (Figure 8).

\section{THE TYPE VI SECRETION SYSTEM OF S. plymuthica A153 IS NOT INVOLVED IN VIRULENCE}

The bacterial Type VI secretion system (T6SS) is the most recently described secretion system in Gram-negative bacteria and has been found to promote bacterial virulence against both prokaryotic competitors and eukaryote hosts (Coulthurst, 2013). In silico analyses revealed that a T6SS gene cluster highly homologous to that present in Citrobacter rodentium ICC168 is present in the genome of A153 (Matilla and Salmond, unpublished results). The role of the T6SS in virulence against nematodes remains largely uncharacterized but Sana et al. (2012) showed that it plays a role in $P$. aeruginosa "slow killing" of C. elegans. To investigate if the S. plymuthica A153 T6SS is involved in virulence, an A153 T6SS mutant was constructed (A153T6) and characterized. However, no difference in the virulence was observed between A153T6 and the A153 wild-type (Figure 5C).

\section{DISCUSSION}

Although zeamine was first described as a phytotoxin with broadspectrum antibacterial properties (Wu etal., 2010; Zhou et al., 2011), this study showed that zeamine is also a potent nematicide. Furthermore, it is a characteristic of some bacterial toxins that younger hosts are more susceptible than older ones (MahajanMiklos et al., 1999), and consistent with this, C. elegans showed age-dependent sensitivity to the A153 nematicide. In addition, we have shown that zeamine is capable of killing $S$. cerevisiae and $S$. pombe, and therefore zeamine, by definition, is also a fungicide. This leads us to conclude that zeamine is a very broad-spectrum antibiotic that is capable of antagonizing a phylogenetically diverse set of organisms, making it unsuitable, in an unmodified form, for application as a therapeutic antibiotic. 
Like the fabclavines (Fuchs et al., 2014), the zeamine molecule has a polyaminated fatty acid backbone that is derived from modified secondary lipid metabolism (Wu et al., 2010; Masschelein et al., 2013). Zeamine also shows some structural similarity with compounds such as the phytotoxin syringomycin, which has been shown to antagonize plant cells by forming ion channels in the plant cell membrane (Hutchison and Gross, 1997). Altogether, it is possible that zeamine has lipophilic properties and might interact with the lipids of cell membranes through a mechanism analogous to that of cationic antimicrobial peptides (Hancock, 2001). A membranal target would be entirely consistent with the observed strong susceptibility of very diverse organisms to zeamine.

Fatty acids have been shown previously to function as nematicides against various phytopathogenic nematodes, and have been hypothesized to disrupt plasma membranes to facilitate solubilization of the nematode cuticle or hypodermis (Anke et al., 1995; Davis et al., 1997). Similarly, cationic peptides are capable of interacting with and disrupting cell membranes owing to a three-dimensional amphiphilic structure (Joondan et al., 2014), and various classes thereof have been shown effective against fungi, protozoa and mammalian cells (Hancock, 2001). Intriguingly, cationic peptides share many of these properties with zeamine, and have been shown previously to function as nematicides (Colgrave et al., 2008), and are capable of causing severe damage to the intestine of lepidopteran larvae (Barbeta et al., 2008). It is therefore possible that the nematicidal cytotoxicity of zeamine involves damage to, and vacuolisation of, the cells that line the C. elegans intestine.

Our results raise questions about the role of zeamine in nature. The majority of sequenced S. plymuthica strains that carry the $z m n$ gene cluster were isolated from agricultural contexts, such as the plant antho- and rhizosphere (e.g., Åström and Gerhardson, 1988; Fürnkranz et al., 2012; Neupane et al., 2012a,b,c). Plant root exudates are rich in sugars and other organic nutrients that favor root colonization by soil-borne bacteria (Bais et al., 2006), and this study has shown that different sugars have different effects on zeamine production by $\mathrm{A} 153$ - with some repressing the production of the antibiotic whilst others favor it. In this regard, it is notable that A153 was initially isolated on the basis that it antagonized plant growth (Åström and Gerhardson, 1988), and that zeamine has been found to be a potent phytotoxin, capable of antagonizing both shoot and root development in rice seedlings (Zhou et al., 2011). Together with our results showing that zeamine is also a potent nematicide, these observations raise the question: are there any possible large-scale effects of zeamine production by rhizosphere-associated soil bacteria?

Various Dickeya spp. are pathogens of plants, and as some of these have been found to contain the $z m n$ gene cluster, their nematicidal properties were investigated. However, contrary to expectation, none of the selected strains were found to show fastkilling of $C$. elegans. The absence of genes zmn1-4 in strains of Dickeya suggests that the cryptic zmn gene clusters of the assayed Dickeya isolates may not be effectively or functionally expressed, correlating with a lack of rapid nematicidal activity. Alternatively, and considering the low sequence conservation between Serratia and Dickeya zmn9, it is possible that the final biosynthetic products of the $z m n$ gene clusters of the Dickeya strains analyzed in this study do not possess the same biological properties as zeamine. For example, Masschelein et al. (2013) showed that S. plymuthica RVH1 is capable of producing three different zeamine molecules (zeamine, zeamine I, and zeamine II), of which zeamine I is the predominant molecule produced by D. zeae EC1 (Wu etal., 2010). The individual contributions of these molecules to the antibiotic activity of zeamine, sensu lato, is unclear, although further work on this topic might reveal differential toxic activities between different zeamines and derived molecules. If different zeamine species are found to show differential specific toxicities, this would raise the possibility that these may be used as more-specific antibiotics or pesticides. It is also possible that the zmn gene clusters of the Dickeya isolates tested in this study are simply cryptic under the conditions tested - as is known for gene clusters encoding other secondary metabolites (Osbourn, 2010). It is, however, clear that various Dickeya spp. are virulent in the $C$. elegans model, consistent with previous work that found that the plant pathogens D. dadantii 3937c, Agrobacterium tumefaciens CFBP2413, and Pectobacterium carotovorum CFBP 2141, are capable of killing C. elegans through infection (Couillault and Ewbank, 2002).

The expression pattern of the A153 zmn gene cluster is characteristic for secondary metabolite antibiotics, which are typically produced during conditions of nutrient limitation and reduced growth (Bibb, 2005). As is common with secondary metabolites, transcription of $z m n$ biosynthetic genes is sensitive to environmental conditions. In contrast to findings in other bacteria such as S. plymuthica RVH1 (Masschelein et al., 2013), zmn gene transcription in A153 does not appear to be thermoregulated (Figure S2). Zeamine production does, however, show media-dependent effects in A153, as has previously been reported for D. zeae EC1 (Zhou et al., 2011). The basis of this effect appears to be post-transcriptional, as we did not observe a correlation between $z m n$ gene transcription and zeamine bioactivity between different carbon sources (cf. Figure 7B; Table S4).

We observed a correlation between zmn gene transcription and the activity of the RNA chaperone Hfq - with the A153 $z m n$ gene cluster being silent in a $\Delta h f q$ background - consistent with its role as a regulator of secondary metabolism in other species of Serratia. Mutation of $h f q$ has been shown previously to reduce the transcription of genes involved in iron uptake in E. coli (Večerek et al., 2003), and intriguingly, as part of our mutagenesis program, we isolated a mutant (A153JH11) with a transposon insertion in the A153 homolog of the ferric aerobactin receptor (Figure S3A), which showed increased production of zeamine (Figure S3B), suggesting that production of the antibiotic is increased during conditions that might mimic iron limitation.

In summary, the work presented in this study has shown that S. plymuthica A153 produces the very broad-spectrum antibiotic, zeamine. Although zeamine was initially described as a phytotoxin with antibacterial activity, our results show that zeamine is also a potent nematicidal compound and antifungal. That zeamine antagonizes such a phylogenetically diverse set of organisms suggests that it targets a highly conserved cellular process, which 
would make it unsuitable as a specific antibiotic. That target is likely to be the cell membranes of diverse hosts. However, the research presented here may help toward the development of zeamine analogs with enhanced host specificity in nematodes and fungi.

\section{ACKNOWLEDGMENTS}

We thank Ian Toth, Richard Cooper, Juan Mata, and Steve Oliver for generous donations of bacterial and fungal strains. The DH26 nematode strain was provided by the Caenorhabditis Genetics Center. We would also like to thank Eric Miska and Peter Sarkies for advice on the C. elegans virulence assay and Alison Drew for technical support. MAMV was supported by the EU Marie-Curie Intra-European Fellowship for Career Development (FP7-PEOPLE-2011-IEF), grant number 298003. The Salmond laboratory is supported by funding through the Biotechnology and Biological Sciences Research Council (BBSRC; UK). Work with plant pathogens was carried out under DEFRA licence No. 50864/197900/1.

\section{SUPPLEMENTARY MATERIAL}

The Supplementary Material for this article can be found online at: http://www.frontiersin.org/journal/10.3389/fmicb.2015.00137/ abstract

\section{REFERENCES}

Aballay, A., Yorgey, P., and Ausubel, F. M. (2000). Salmonella typhimurium proliferates and establishes a persistent infection in the intestine of Caenorhabditis elegans. Curr. Biol. 10, 1539-1542. doi: 10.1016/S0960-9822(00)00830-7

Anke, H., Stadler, M., Mayer, A., and Sterner, O. (1995). Secondary metabolites with nematicidal and antimicrobial activity from nematophagous fungi and Ascomycetes. Can. J. Bot. 73, S932-S939. doi: 10.1139/b95-341

Åström, B., and Gerhardson, B. (1988). Differential reactions of wheat and pea genotypes to root inoculation with growth-affecting rhizosphere bacteria. Plant Soil 109, 263-269. doi: 10.1007/BF02202093

Babitzke, P., and Romeo, T. (2007). CsrB sRNA family: sequestration of RNA-binding regulatory proteins. Curr. Opin. Microbiol. 10, 156-163. doi: 10.1016/j.mib.2007.03.007

Bais, H. P., Weir, T. L., Perry, L. G., Gilroy, S., and Vivanco, J. M. (2006). The role of root exudates in rhizosphere interactions with plants and other organisms. Annu. Rev. Plant Biol. 57, 233-266. doi: 10.1146/annurev.arplant.57.032905.105159

Barbeta, B. L., Marshall, A. T., Gillon, A. D., Craik, D. J., and Anderson, M. A. (2008). Plant cyclotides disrupt epithelial cells in the midgut of lepidopteran larvae. Proc. Natl. Acad. Sci. U.S.A. 105, 1221-1225. doi: 10.1073/pnas.0710338104

Bibb, M. I. (2005). Regulation of secondary metabolism in Streptomyces. Curr. Opin. Microbiol. 8, 208-215. doi: 10.1016/j.mib.2005.02.016

Brenner, S. (1974). The genetics of Caenorhabditis elegans. Genetics 77, 71-94.

Burlinson, P., Studholme, D., Cambray-Young, J., Heavens, D., Rathjen, J., Hodgkin, J., et al. (2013). Pseudomonas fluorescens NZI7 repels grazing by C. elegans, a natural predator. ISME J. 7, 1126-1138. doi: 10.1038/ismej.2013.9

Cezairliyan, B., Vinayavekhin, N., Grenfell-Lee, D., Yuen, G. J., Saghatelian, A., and Ausubel, F. M. (2013). Identification of Pseudomonas aeruginosa phenazines that kill Caenorhabditis elegans. PLOS Pathog. 9:e1003101. doi: 10.1371/journal.ppat.1003101

Challis, G. L., and Hopwood, D. A. (2003). Synergy and contingency as driving forces for the evolution of multiple secondary metabolite production by Streptomyces species. Proc. Natl. Acad. Sci. U.S.A. 100, 14555-14561. doi: 10.1073/pnas. 1934677100

Chitwood, D. J. (2002). Phytochemical based strategies for nematode control. Annu. Rev. Phytopathol. 40, 221-249. doi: 10.1146/annurev.phyto.40.032602.130045

Colgrave, M. L., Kotze, A. C., Huang, Y. H., O’Grady, J., Simonsen, S. M., and Craik, D. J. (2008). Cyclotides: natural, circular plant peptides that possess significant activity against gastrointestinal nematode parasites of sheep. Biochemistry 47, 5581-5589. doi: 10.1021/bi800223y
Couillault, C., and Ewbank, J. J. (2002). Diverse bacteria are pathogens of Caenorhabditis elegans. Infect. Immun. 70, 4705-4707. doi: 10.1128/IAI.70.8.4705-47 07.2002

Coulthurst, S. J. (2013). The Type VI secretion system-a widespread and versatile cell targeting system. Res. Microbiol. 164, 640-654. doi: 10.1016/j.resmic.2013. 03.017

Coulthurst, S. J., Kurz, C. L., and Salmond, G. P. C. (2004). luxS mutants of Serratia defective in autoinducer-2-dependent 'quorum sensing' show straindependent impacts on virulence and production of carbapanem and prodigiosin. Microbiology 150, 1901-1910. doi: 10.1099/mic.0.26946-0

Czajkowski, R., De Boer, W. J., Van Veen, J. A., and Van der Wolf, J. M. (2012). Characterization of bacterial isolates from rotting potato tuber tissue showing antagonism to Dickeya sp. biovar 3 in vitro and in planta. Plant Pathol. 61, 169-182. doi: 10.1111/j.1365-3059.2011.02486.x

Davis, E. L., Meyers, D. M., Dullum, C. J., and Feitelson, J. S. (1997). Nematicidal activity of fatty acid esters on soybean cyst and root-knot nematodes. J. Nematol. 29, 677-684.

Delcher, A. L., Harmon, D., Kasif, S., White, O., and Salzberg, S. L. (1999). Improved microbial gene identification with GLIMMER. Nucleic Acids Res. 27, 4636-4641. doi: 10.1093/nar/27.23.4636

de Lorenzo, V., Herrero, M., Jakubzik, U., and Timmis, K. N. (1990). Mini-Tn5 transposon derivatives for insertion mutagenesis, promoter probing, and chromosomal insertion of cloned DNA in Gram negative eubacteria. J. Bacteriol. 172, 6568-6572.

Demarre, G., Guerout, A. M., Matsumoto-Mashimo, C., Rowe-Magnus, D. A., Marliere, P., and Mazel, D. (2005). A new family of mobilizable suicide plasmids based on broad host range R388 plasmid (IncW) and RP4 plasmid ( $\operatorname{IncP} \alpha$ ) conjugative machineries and their conjugant Escherichia coli host strains. Res. Microbiol. 156, 245-255. doi: 10.1016/j.resmic.2004.09.007

De Vleesschauwer, D., and Höfte, M. (2003). Using Serratia plymuthica to control fungal pathogens of plants. CAB Rev. 2:046. doi: 10.1079/PAVSNNR200 72046

Fineran, P. C., Slater, H., Everson, L., Hughes, K., and Salmond, G. P. (2005). Biosynthesis of tripyrrole and $\beta$-lactam secondary metabolites in Serratia: integration of quorum sensing with multiple new regulatory components in the control of prodigiosin and carbapenem antibiotic production. Mol. Microbiol. 56, 1495-1517. doi: 10.1111/j.1365-2958.2005.04660.x

Frazer, K. A., Pachter, L., Poliakov, A., Rubin, E. M., and Dubchak, I. (2004). VISTA. Computational tools for comparative genomics. Nucleic Acids Res. 32, W273-W279. doi: 10.1093/nar/gkh458

Fuchs, S. W., Grundmann, F., Kurz, M., Kaiser, M., and Bode, H. B. (2014). Fabclavines: bioactive peptide-polyketide-polyamino hybrids from Xenorhabdus. ChemBioChem 15, 512-516. doi: 10.1002/cbic.201300802

Fürnkranz, M., Lukesch, B., Müller, H., Huss, H., Grube, M., and Berg, G. (2012). Microbial diversity inside pumpkins: microhabitat-specific communities display a high antagonistic potential against phytopathogens. Microb. Ecol. 63, 418-428. doi: 10.1007/s00248-011-9942-4

Gems, D., Sutton, A. J., Sundermeyer, M. L., Albert, P. S., King, K. V., Edgley, M. L., et al. (1998). Two pleiotropic classes of daf-2 mutation affect larval arrest, adult behavior, reproduction and longevity in Caenorhabditis elegans. Genetics 150, 129-155.

Gould, M., Nelson, L. M., Waterer, D., and Hynes, R. K. (2008). Biocontrol of Fusarium sambucinum, dry rot of potato, by Serratia plymuthica 5-6. Biocontrol Sci. Technol. 18, 1005-1016. doi: 10.1080/09583150802478189

Grimont, P. A., and Grimont, F. (1978). The genus Serratia. Annu. Rev. Microbiol. 32, 221-248. doi: 10.1146/annurev.mi.32.100178.001253

Hancock, R. E. W. (2001). Cationic peptides: effectors in innate immunity and novel antimicrobials. Lancet Infect. Dis. 1, 156-164. doi: 10.1016/S14733099(01)00092-5

Hedges, S. B., Dudley, J., and Kumar, S. (2006). TimeTree: a public knowledgebase of divergence times among organisms. Bioinformatics 22, 2971-2972. doi: 10.1093/bioinformatics/btl505

Hutchison, M. L., and Gross, D. C. (1997). Lipopeptide phytotoxins produced by Pseudomonas syringae pv. syringae: comparison of the biosurfactant and ion channel-forming activities of syringopeptin and syringomycin. Mol. Plant Microbe Interact. 10, 347-354. doi: 10.1094/MPMI.1997.10.3.347

Jones, J. T., Haegeman, A., Danchin, E. G., Gaur, H. S., Helder, J., Jones, M. G., et al. (2013). Top 10 plant-parasitic nematodes in molecular plant pathology. Mol. Plant Pathol. 14, 946-961. doi: 10.1111/mpp.12057 
Joondan, N., Jhaumeer-Laulloo, S., and Caumul, P. (2014). A study of the antibacterial activity of L-Phenylalanine and L-Tyrosine esters in relation to their CMCs and their interactions with 1,2-dipalmitoyl-sn-glycero-3phosphocholine, DPPC as model membrane. Microbiol. Res. 169, 675-685. doi: 10.1016/j.micres.2014.02.010

Kamensky, M., Ovadis, M., Chet, I., and Chernin, L. (2003). Soil-borne strain IC14 of Serratia plymuthica with multiple mechanisms of antifungal activity provides biocontrol of Botrytis cinerea and Sclerotinia sclerotiorum diseases. Soil Biol. Biochem. 35, 323-331. doi: 10.1016/S0038-0717(02)0 0283-3

Kurz, C. L., Chauvet, S., Andrès, E., Aurouze, M., Vallet, I., and Michel, G. P., et al. (2003). Virulence factors of the human opportunistic pathogen Serratia marcescens identified by in vivo screening. EMBO J. 22, 1451-1460. doi: 10.1093/emboj/cdg159

Kurz, C. L., and Ewbank, J. J. (2000). Caenorhabditis elegans for the study of host-pathogen interactions. Trends Microbiol. 8, 142-144. doi: 10.1016/S0966842X(99)01691-1

Laws, T. R., Harding, S. V., Smith, M. P., Atkins, T. P., and Titball, R. W. (2004). Age influences resistance of Caenorhabditis elegans to killing by pathogenic bacteria. FEMS Microbiol. Lett. 234, 281-287. doi: 10.1111/j.1574-6968.2004.tb0 9545.x

Levenfors, J. J., Hedman, R., Thaning, C., Gerhardson, B., and Welch, C. J. (2004). Broad-spectrum antifungal metabolites produced by the soil bacterium Serratia plymuthica A 153. Soil Biol. Biochem. 36, 677-685. doi: 10.1016/j.soilbio.2003.12.008

Liu, X., Bimerew, M., Ma, Y., Müller, H., Ovadis, M., Eberl, L., et al. (2007). Quorumsensing signaling is required for production of the antibiotic pyrrolnitrin in a rhizospheric biocontrol strain of Serratia plymuthica. FEMS Microbiol. Lett. 270 299-305. doi: 10.1111/j.1574-6968.2007.00681.x

Mahajan-Miklos, S., Tan, M.-W., Rahme, L. G., and Ausubel, F. M. (1999). Molecular mechanisms of bacterial virulence elucidated using a Pseudomonas aeruginosaCaenorhabditis elegans pathogensis model. Cell 96, 47-56. doi: 10.1016/S00928674(00)80958-7

Marchler-Bauer, A., Lu, S., Anderson, J. B., Chitsaz, F., Derbyshire, M. K., DeWeese-Scott, C., et al. (2011). CDD: a conserved domain database for the functional annotation of proteins. Nucleic Acids Res. 39, D225-D229. doi: 10.1093/nar/gkq1189

Masschelein, J., Mattheus, W., Gao, L. J., Moons, P., Van Houdt, R., Uytterhoeven, B., etal. (2013). A PKS/NRPS/FAS hybrid gene cluster from Serratia plymuthica RVH1 encoding the biosynthesis of three broad spectrum, zeamine-related antibiotics. PLoS ONE 8:e54143. doi: 10.1371/journal.pone.00 54143

Matilla, M. A., and Salmond, G. P. (2014). The viunalikevirus, bacteriophage фMAM1, is a broad host-range, high efficiency generalised transducing phage that infects environmental and clinical isolates of the enterobacteria, Serratia and Kluyvera. Appl. Environ. Microbiol. 80, 6446-6457. doi: 10.1128/AEM.015 46-14

Matilla, M. A., Stöckmann, H., Leeper, F. J., and Salmond, G. P. (2012) Bacterial biosynthetic gene clusters encoding the anti-cancer haterumalide class of molecules: biogenesis of the broad spectrum antifungal and antioomycete compound, oocydin A. J. Biol. Chem. 287, 39125-39138. doi: 10.1074/jbc.M112.401026

Mazzola, M., Cook, R. J., Thomashow, L. S., Weller, D. M., and Pierson, L. S. (1992). Contribution of phenazine antibiotic biosynthesis to the ecological competence of fluorescent pseudomonads in soil habitats. Appl. Environ. Microbiol. 58, 26162624.

Meziane, H., Gavriel, S., Ismailov, Z., Chet, I., Chernin, L., and Höfte, M. (2006) Control of green and blue mould on orange fruit by Serratia plymuthica strains IC14 and IC1270 and putative modes of action. Postharvest Biol. Technol. 39, 125-133. doi: 10.1016/j.postharvbio.2005.10.007

Neupane, S., Högberg, N., Ahlström, S., Lucas, S., Han, J., Lapidus, A., et al. (2012a). Complete genome sequence of the rapseed plant-growth promoting Serratia plymuthica strain AS9. Stand. Genomic Sci. 6, 54-62. doi: 10.4056/sigs. 25 95762

Neupane, S., Finlay, R. D., Alström, S., Goodwin, L., Kyrpides, N. C., Lucas, S., et al. (2012b). Complete genome sequence of Serratia plymuthica strain AS12. Stand. Genomic Sci. 6, 165-173. doi: 10.4056/sigs.27 05996
Neupane, S., Finlay, R. D., Kyrpides, N. C., Goodwin, L., Ahlström, S., Lucas, S., et al. (2012c). Complete genome sequence of the plast-associated Serratia plymuthica strain AS13. Stand. Genomic Sci. 7, 22-30. doi: 10.4056/sigs.2 966299

Osbourn, A. (2010). Secondary metabolic gene clusters: evolutionary toolkits for chemical innovation. Trends Genet. 26, 449-457. doi: 10.1016/j.tig.2010. 07.001

Perego, M., Cole, S. P., Burbulys, D., Trach, K., and Hoch, J. A. (1989). Characterization of the gene for a protein kinase which phosphorylates the sporulation-regulatory proteins Spo0A and Spo0F of Bacillus subtilis. J. Bacteriol. 171, 6187-6196.

Portal-Celhay, C., Bradley, E. R., and Blaser, M. J. (2012). Control of bacterial proliferation in regulation of lifespan in Caenorahbditis elegans. BMC Microbiol. 12:49. doi: 10.1186/1471-2180-12-49

Pradel, E., Zhang, Y., Pujol, N., Matsuyama, T., Bargmann, C. I., and Ewbank, J. J. (2007). Detection and avoidance of a natural product from the pathogenic bacterium Serratia marscences by Caenorhabditis elegans. Proc. Natl. Acad. Sci. U.S.A. 104, 2295-2300. doi: 10.1073/pnas.0610 281104

Price-Whelan, A., Dietrich, L. E., and Newman, D. K. (2006). Rethinking 'secondary' metabolism: physiological roles for phenazine antibiotics. Nature Chem. Biol. 2, 71-78. doi: 10.1038/nchembio764

Pritchard, L., Humphris, S., Baeyen, S., Maes, M., Van Vaerenbergh, J., Elphinstone, J., et al. (2013a). Draft genome sequences of four Dickeya dianthicola and four Dickeya solani strains. Genome Announc. 1, e00087-e00112. doi: 10.1128/genomeA.00087-12

Pritchard, L., Humphris, S., Saddler, G. S., Elphinstone, J. G., Pirhonen, M., and Toth, I. K. (2013b). Draft genome sequences of 17 isolates of the plant pathogenic bacterium Dickeya. Genome Announc. 1, e00978-e00913. doi: 10.1128/genomeA.00978-13

Rahme, L. G., Ausubel, F. M., Cao, H., Drenkard, E., Goumnerov, B. C., Lau, G. W., et al. (2000). Plants and animals share functionally common bacterial virulence factors. Proc. Natl. Acad. Sci. U.S.A. 97, 8815-8821. doi: 10.1073/pnas.97.1 6.8815

Ramsay, J. P. (2013). High-throughput $\beta$-galactosidase and $\beta$-glucuronidase assays using fluorogenic substrates. Bio-Protocol. 3:e827.

Roberts, K. J. (2010). Quorum Sensing in the Mouse Intestinal Pathogen Citrobacter rodentium. Ph.D. thesis, University of Cambridge, Cambridge.

Sambrook, J., Fritsch, E. F., and Maniatis, T. (1989). Molecular Cloning, Vol. 2. New York: Cold Spring Harbor Laboratory Press, 14-29.

Sana, T. G., Hachani, A., Bucior, I., Soscia, C., Garvis, S., Termine, E., et al. (2012). The second type VI secretion system of Pseudomonas aeruginosa strain $\mathrm{PAO} 1$ is regulated by quorum sensing and Fur and modulates internalization in epithelial cells. J. Biol. Chem. 287, 27095-27105. doi: 10.1074/jbc.M112.3 76368

Sattely, E. S., Fischbach, M. A., and Walsh, C. T. (2008). Total biosynthesis: in vitro reconstitution of polyketide and nonribosomal peptide pathways. Nat. Prod. Rep. 25, 757-793. doi: 10.1039/b801747f

Sifri, C. D., Begun, J., and Ausubel, F. M. (2005). The worm has turned - microbial virulence modeled in Caenorhabditis elegans. Trends Microbiol. 13, 119-127. doi: 10.1016/j.tim.2005.01.003

Thaning, C., Welch, C. J., Borowicz, J. J., Hedman, R., and Gerhardson, B. (2001). Suppression of Sclerotinia sclerotiorum apothecial formation by the soil bacterium Serratia plymuthica: identification of a chlorinated macrolide as one of the causal agents. Soil Biol. Biochem. 33, 1817-1826. doi: 10.1016/S0038-0717(01)0 0109-2

Večerek, B., Moll, I., Afonyushkin, T., Kaberdin, V., and Bläsi, U. (2003). Interaction of the RNA chaperone Hfq with mRNAs: direct and indirect roles of Hfq in iron metabolism of Escherichia coli. Mol. Microbiol. 50, 897-909. doi: 10.1046/j.13652958.2003.03727.x

Vogel, J., and Luisi, B. F. (2011). Hfq and its constellation of RNA. Nat. Rev. Microbiol. 9, 578-589. doi: 10.1038/nrmicro2615

Wei, J. Z., Hale, K., Carta, L., Platzer, E., Wong, C., Fang, S. C., et al. (2003). Bacillus thuringiensis crystal proteins that target nematodes. Proc. Natl. Acad. Sci. U.S.A. 100, 2760-2765. doi: 10.1073/pnas.0538072100

Wilf, N. M., Williamson, N. R., Ramsay, J. P., Poulter, S., Bandyra, K. J., and Salmond, G. P. C. (2012). The RNA chaperone, Hfq, controls two luxR-type regulators and plays a key role in pathogenesis and production of antibiotics in 
Serratia sp. ATCC39006. Environ. Microbiol. 13, 2649-2666. doi: 10.1111/j.14622920.2011.02532.x

Wu, J., Zhang, H. B., Xu, J. L., Cox, R. J., Simpson, T. J., and Zhang, L. H. (2010). 13C labeling reveals multiple amination reactions in the biosynthesis of a novel polyketide polyamine antibiotic zeamine from Dickeya zeae. Chem. Commun. 46, 333-335. doi: 10.1039/b916307g

Zhou, J., Zhang, H., Wu, J., Liu, Q., Xi, P., Lee, J., et al. (2011). A novel multidomain polyketide synthase is essential for zeamine production and the virulence of Dickeya zeae. Mol. Plant Microbe Interact. 24, 1156-1164. doi: 10.1094/MPMI-04-11-0087

Conflict of Interest Statement: The authors declare that the research was conducted in the absence of any commercial or financial relationships that could be construed as a potential conflict of interest.
Received: 13 January 2015; paper pending published: 26 January 2015; accepted: 05 February 2015; published online: 26 February 2015.

Citation: Hellberg JEEU, Matilla MA and Salmond GPC (2015) The broad-spectrum antibiotic, zeamine, kills the nematode worm Caenorhabditis elegans. Front. Microbiol. 6:137. doi: 10.3389/fmicb.2015.00137

This article was submitted to Systems Microbiology, a section of the journal Frontiers in Microbiology.

Copyright (c) 2015 Hellberg, Matilla and Salmond. This is an open-access article distributed under the terms of the Creative Commons Attribution License (CC BY). The use, distribution or reproduction in other forums is permitted, provided the original author(s) or licensor are credited and that the original publication in this journal is cited, in accordance with accepted academic practice. No use, distribution or reproduction is permitted which does not comply with these terms. 